\title{
WHAT YOU CAN'T SEE CAN HURT YOU
}

\section{How do stereotyping, implicit bias and stereotype threat affect Māori health?}

\author{
Carla A. Houkamau*
}

\begin{abstract}
A number of studies demonstrate Māori receive a poorer standard of healthcare than Pākehā and other non-Māori in New Zealand. Implicit bias on the part of healthcare providers has been cited as a key contributor to health inequities internationally; however, the concept has not yet been explored in relation to Māori health. This paper addresses that research gap and describes a theoretical basis for further research on the role of bias for Māori health outcomes. Drawing from empirical research and theories formulated in social psychology, the paper considers the relevance of implicit bias, stereotyping and stereotype threat for Māori health outcomes. These have not been integrated and applied to the problem of Māori health inequities per se; however, it is proposed that they provide a useful conceptual lens for understanding how interpersonal dynamics between Māori and Pākehā help perpetuate health disparities. Suggestions for further research are also made.
\end{abstract}

\section{Keywords}

Māori, health equity, stereotype threat, implicit bias, Indigenous

* Ngāti Porou (Te Whānau o Tu Whakairiora), Ngāti Kahungunu (Ngāti Kere). Senior Lecturer, Faculty of Business and Economics, University of Auckland, New Zealand. Email: c.houkamau@auckland.ac.nz 


\section{Introduction}

Striving for equity in healthcare and health outcomes for Māori is woven into official government policy in New Zealand (Ministry of Health, 2014). Cultural competence is taught in New Zealand's undergraduate medical programmes and forms part of the New Zealand Medical Council's standards framework. Despite these efforts, limited progress has been made in reducing Māori health disparities. Year after year, Māori continue to have the poorest health status of any group in New Zealand (Ministry of Health, 2015).

A complex range of variables contribute to this situation. Inequities in health reflect inequities in society. Māori are overrepresented in low socioeconomic groups, making it more difficult for Māori to afford quality health services or indeed any health services at all (Marriott \& Sim, 2014). Income inequality is associated with a range of adverse life conditions which negatively influence health (Lynch, Davey Smith, Kaplan, \& House, 2000). When it comes to accessing healthcare, Māori face multiple barriers (Jansen, Bacal, \& Crengle, 2008). Institutional level barriers include the universal, Western approach to healthcare and the underrepresentation of Māori in the health professions. Human resource-level barriers include the characteristics of non-Māori health professionals and their attitudes towards Māori patients.

Notwithstanding the need to address systemic and institutional racism (Brown, 2016; Came, 2012, 2014), this paper focuses on barriers to Māori health equity which stem from the interpersonal dynamics between Māori and non-Māori as they interface in healthcare settings. The theoretical concepts invoked relate to a vast body of research grounded in social identity theory which was developed to explain human behaviour in intergroup contexts (Tajfel $\&$ Turner, 1986). Studies within the social identity paradigm have consistently demonstrated humans are automatically inclined to favour their own group (i.e., their in-group) and automatically attach negative stereotypes to out-group members (i.e., people who belong to social groups other than their own) (Banaji, 2013; Dovidio \& Gaertner, 2010; Greenwald \& Banaji, 1995, 2013; Greenwald et al., 2002). These in-group/out-group dynamics mean that ethnic minorities are disadvantaged in their routine interactions with members of dominant ethnic groups-not only because of their minority status, but also because negative societal stereotypes of their group may influence how they are treated and perceived by dominant group members (Chambers et al., 1998; Joiner, Katz, \& Kwon, 2002; Tatum, 1997).

Although significant efforts are being made to increase the number of Māori healthcare providers at the current time (Curtis et al., 2015), Māori are a minority in the healthcare workforce, meaning the vast majority of interactions Māori have are with healthcare providers who are non-Māori. Social identity theory posits that because Māori are likely to be perceived as outgroup members in most of their dealings with healthcare professionals, they are more likely to be vulnerable to stereotyping and implicit biases that may arise.

Implicit bias is the process by which societal stereotypes are triggered during person perception. Implicit biases are sometimes referred to as unconscious because they occur outside of the perceiver's conscious awareness (Dovidio $\&$ Gaertner, 2010). A significant body of research has demonstrated that those who hold very strong negative implicit biases about ethnic minorities consciously consider themselves fairminded (Greenwald \& Banaji, 2013). In this way, implicit biases are a form of unconscious racism that reflect widely held stereotypes of particular groups. The existence of implicit biases has been used to explain why inequities continue to exist in society even though declared, explicit racist attitudes are less prevalent (Amodio, 2014).

According to Blair, Steiner and Havranek (2011), implicit bias in healthcare occurs when 
a healthcare provider automatically classifies a patient as a member of a group and applies stereotypical characterisations of the group, whether positive or negative, to the individual. Stone and Moskowitz (2011) have observed that implicit biases, although unconscious, may negatively influence how medical professionals interact with minority group patients. This, in turn, compromises health provider-patient rapport, fosters patient mistrust and dissatisfaction, and may ultimately lead to poorer healthcare (Teal, Gill, Green, \& Crandall, 2012).

It is not only health providers who hold biases. Minority patients who anticipate poorer treatment from health providers may enter healthcare settings hypersensitive to discrimination. Aronson, Burgess, Phelan and Juarez (2013) have observed that, when wary of being stereotyped by health providers, patients may inadvertently reinforce the negative stereotypes of their group due to anxiety and fear of being judged. This process is known as stereotype threat.

The following sections discuss the relevance of stereotyping, implicit bias, and stereotype threat to Māori health outcomes in relation to four lines of evidence. First, empirical studies have found providers' treatment of Māori patients differs from that of non-Māori. Second, several studies show that some Māori express dissatisfaction with non-Māori healthcare providers. Third, studies show that some non-Māori practitioners hold quite negative stereotypes about Māori healthcare users. Finally, research has found that some Māori report anxiety about going to healthcare providers for fear of being stereotyped.

\section{Do Māori receive poorer-quality healthcare?}

A range of studies have found differences in the way medical services, procedures and treatments are prescribed for Māori as opposed to other ethnic groups (Alexander, Irwin, Purdie,
\& Hunn, 2010; Arroll, Goodyear-Smith, \& Lloyd, 2002; Brewer et al., 2012; EllisonLoschmann et al., 2015).

For example, in a seminal piece of research, Mitchell (1991) examined ethnic inequalities in childhood asthma in New Zealand and found "major ethnic differences in asthma drug management both in the community and at the time of discharge from hospital" (p. 831). Specifically, he found New Zealand general practitioners (GPs) are less likely to prescribe prophylactic therapy to Māori and Polynesian children. According to Mitchell, anecdotal evidence suggests this is because Pākehā GPs find it difficult to explain treatment instructions to Māori and Polynesian parents. This, he notes, amounts to stereotyping according to ethnicity-because medical practitioners make "assumptions about the appropriateness of prescribing asthma prophylactic therapy for these ethnic minority groups" (p. 835).

More recent research compared survival rates of 301 Māori and 328 non-Māori (mainly Pākehā) patients diagnosed as having colon cancer between 1996 and 2003 (Hill, Sarfati, Blakely, Robson, Purdie, Chen, et al., 2010). Māori had a significantly poorer cancer survival rate than non-Māori even after controlling for demographics or disease characteristics (see also Sneyd, 2008). Examination of the medical notes found that Māori patients were significantly less likely than other ethnic groups to receive chemotherapy and were more likely to experience a delay of at least eight weeks before starting chemotherapy (Hill, Sarfati, Blakely, Robson, Purdie, Dennett, et al., 2010).

Other examples include a study by Westbrooke, Baxter and Hogan (2001) which found Māori men are less likely to receive medical intervention for cardiac disease compared with Pākehā men. Bramley et al. (2004) found Māori are less likely to receive screening for, and treatment of, ischaemic heart disease. In a study of birthing practices in New Zealand, the Ministry of Health (2004) found that Māori women are less likely to receive pain relief during 
labour and childbirth than Pākehā women, while Jansen and Jansen (2013) found that Pākehā doctors spent $17 \%$ less time ( 2 minutes out of a 12-minute consultation) interviewing Māori than patients from other ethnic groups.

As a final example of how Māori receive poorer-quality healthcare, Obertová et al. (2015) examined diagnostic and treatment pathways for Māori and non-Māori/New Zealand European men with prostate cancer. All Māori men (150) diagnosed with prostate cancer in the Midland Cancer Network region between 2007 and 2010 were identified and age-matched with a comparison group of New Zealand European men. Māori men were managed less proactively, leading Obertová et al. (2015) to suggest that these differences were likely to be a "direct consequence of these ethnic differences in medical management" (p. 835).

Against this backdrop, it is not surprising that several publications cite racism as a causative factor for Māori health inequities (e.g., Harris, Cormack, \& Stanley, 2013; Harris et al., 2012).

\section{Māori perceptions of the healthcare system}

Although Māori are diverse, and not all Māori will feel the same way about their experiences, several studies show that some Māori express dissatisfaction with their healthcare providers.

In 1990 the Māori Asthma Review team conducted over 24 community-based hui throughout New Zealand to examine services in place to help Māori asthma sufferers. Over 1,000 Māori from throughout the country participated (Pomare et al., 1991). Data from this review provides personal accounts from Māori, some of whom described their doctors as unsympathetic and unwilling to take the time to explain health issues to them. An "extreme case involved a general practitioner who had an egg-timer on his desk, and who showed patients the door as soon as their time was up" (Pomare et al., 1991, p. 63). Although this study is 25 years old, the findings align with more recent research which indicates some Māori continue to perceive the treatment they receive from non-Māori health providers as less than satisfactory (Ellison-Loschmann $\&$ Pearce, 2000).

For example, Walker, Signal, Russell and Tuhiwai-Ruru (2008) collected interview data from 44 Māori (aged in their early 20s to their mid-70s) affected by cancer (in the Horowhenua, Manawatu and Tairawhiti districts) and found that participants had both positive and negative experiences with their doctors, nurses and hospice staff. While some praised their carers for their attentiveness and communication, others said health professionals, doctors included, were not responsive to their needs (particularly in terms of lack of communication and provision of pain relief). Participants in this study who also worked in the health sector noted that it would be difficult for Māori who were not assertive or proactive to receive the level of care they required.

Jansen et al. (2008) revealed similar findings in a large nationwide survey of Māori consumers of health and disability services. A telephone survey with a random sample of Māori from across the country, combined with face-to-face interviews with a sample of 50 deaf Māori, yielded survey responses from a total of 651 Māori (384 females [59\%] and 267 males [41\%]). Overall, Māori were reasonably satisfied with the healthcare system and the treatment they had received in the six months prior to the study. However, a subgroup of about $20 \%$ of the total sample expressed dissatisfaction. Compared to the rest of those surveyed, this group were more likely to report they felt disrespected by health providers and that health providers did not really care about Māori patients generally.

Finally, a recent study conducted by Pacific Perspectives (2013), which analysed the maternity and healthcare experiences of Māori and Pacific mothers, underlined the stereotyping 
young women experience in their interactions with health professionals. The report revealed this population perceived significant stigma, stating that "young mothers felt interactions with staff stereotyped, judged and stigmatised them" (p. 8).

The perceptions of individuals in these studies are corroborated by larger-scale research which suggests Māori perceive they are subject to discrimination. For example, Harris et al. (2006) used data from the 2002-2003 New Zealand Health Survey to examine the health consequences of self-reported discrimination among Māori $(n=4,101)$ and Pākehā ( $n=6,269)$ descent. Data revealed that Māori were 10 times more likely than Pākehā to report being the targets of racial discrimination.

In sum, several studies show some Māori receive and perceive unfair treatment based on their ethnicity, indicating discrimination contributes to inequalities in health outcomes between Māori and non-Māori.

\section{Non-Māori perspectives and the role of implicit bias}

Research shows that some medical providers and trainee providers hold less than empathetic views of Māori patients and Māori health issues generally. For example, Jones, Henning, Pinnock, Shurluf and Hawken (2013) investigated the attitudes of New Zealand medical students $(n=276)$ and teachers $(n=135)$ towards Māori health curriculum in clinical training. While many teachers and students endorsed the need for education and training in Māori health issues, others expressed extreme and at times negative views of the Māori health curriculum. Qualitative comments from (a small proportion of) respondents indicated they felt they received "too much pointless training" on Māori health issues and cultural needs. One respondent referred to the Māori curriculum as "politically correct nonsense" and "racist" for focusing on Māori as a group.
Johnstone and Read (2000) found similar attitudes among New Zealand psychiatrists. The researchers sent a questionnaire comprised of both closed and open-ended questions to 335 New Zealand psychiatrists asking them to recommend ways to improve mental health services for Māori. Of the 335 approached, 247 psychiatrists $(74 \%)$ responded. Most psychiatrists made thoughtful and positive recommendations about how to improve their training and services for Māori. However, 28 psychiatrists $(11.3 \%)$, all male, New Zealand-born and with 10 or more years' clinical experience, believed that Māori were biologically or genetically predisposed to mental illness. Some of these practitioners were also sceptical of the need to attend specifically to Māori health issues. One stated, "I wish Masters students would stop sending me crap studies like this, about pointless, meaningless, cultural rubbish. They (Māori) only represent about 10 percent of the population, for God's sake" (Johnstone \& Read, 2000, p. 141).

The negative comments and attitudes in these studies indicate the medical profession, as an integral segment of our society, is not immune to racism. It seems that only a small proportion of health providers express overtly racist views and these of course cannot be extrapolated to all healthcare providers. However, the absence of declared racism does not mean that implicit bias is not widespread throughout the health system. Racism does not have to be overt or conscious to have negative implications for patient outcomes (Paradies, Truong, \& Priest, 2014; Reilly, Ogdie, Von Feldt, \& Myers, 2013; Sabin \& Greenwald, 2012; Zestcott, Blair, \& Stone, 2016).

The Implicit Association Test (IAT) was developed to assess the strength of a person's implicit biases (Greenwald, McGhee, \& Schwartz, 1998). Several studies have shown that those who show a strong IAT effect, that is, they automatically associate negative words and concepts with out-group minorities, are more likely to demonstrate overtly racist 
behaviour (Greenwald, Poehlman, Uhlmann, \& Banaji, 2009). However, empirical research on the relationship between implicit bias and patient outcomes in the health arena is not straightforward. Green et al. (2007) found pro-white IAT scores among medical residents to be related to more proactive health treatment for white American patients compared to African American patients. However, Armbrister (2014) did not find an association between rheumatologists' IAT scores and treatment recommendations for white American and African American patients. Similarly, Sabin, Nosek, Greenwald and Rivara (2009) examined the extent to which implicit and explicit biases held by medical doctors $(n=2,535)$ correlated with differences in quality of care for African Americans. While medical doctors showed an implicit preference for white Americans relative to African Americans, there was no significant difference in treatment recommendations for each group.

These studies show that the IAT's ability to predict overtly discriminatory treatment is limited. This does not mean implicit bias should be discounted as an important psychosocial factor maintaining health inequities, however. Meta-analytic reviews conducted by Oswald, Mitchell, Blanton, Jaccard and Tetlock (2013) and Hall et al. (2015) have concluded that, overall, most healthcare providers appear to have implicit bias in terms of positive attitudes towards whites and negative attitudes towards people of colour and while these may not always lead to differential treatment processes, those biases compromise patient-provider interactions.

To clarify how provider biases' impact on their relationships with their patients Blair et al. (2013) compared clinicians' scores on tests of implicit and explicit biases and perceptions of care among their patients. A telephone survey was sent to 2,908 patients who routinely received care from one of 134 clinicians who had previously completed tests of explicit and implicit ethnic/racial bias. The Primary
Care Assessment Survey was used to measure patients' perceptions of their clinician in relation to interpersonal treatment, communication, trust and contextual knowledge. Respondents were asked to rate their clinicians on the extent to which they "show caring and concern", how often the respondents left the office with "unanswered questions", and the extent to which the respondents trusted their knowledge. Clinicians with higher implicit biases were rated less favourably on all interpersonal variables by African American patients compared with a matched group of white American patients.

Cooper et al. (2012) provided insight into some of the factors that may shape such patient perceptions. They examined associations of clinicians' implicit attitudes about race with visit communication and patient ratings of care between white American doctors and their patients using audio recordings of office visits among 40 physicians and 269 patients in Baltimore, Maryland. Most of the patients (79\%) were African American. Two implicit attitudes about race among clinicians were measured. One measure assessed general racebased bias, the second measure assessed racial bias regarding patient compliance (compliant patients were defined as being willing, reliable and helpful). As expected, higher IAT measures were consistently associated with African Americans' poor ratings of patient care. When clinicians held higher race-based biases, this was associated with more clinician verbal dominance (i.e., clinicians were more likely to dominate the conversations they had with African American patients). In turn, African American clients were likely to feel disrespected, less trusting, less engaged and less satisfied with how their physicians treated them.

Thus, while implicit bias may not lead to overt discrimination, when the provider and the patient come from different cultural or racial groups, health providers may be less effective at establishing a good rapport with their clients (Blair et al., 2014). Dovidio, Kawakami and Gaertner (2002) have shown that implicit 
attitudes "leak" during interactions through the display of negative non-verbal behaviours, meaning that those with higher implicit biases may be perceived as less friendly by out-group minorities. While the small things doctors do, including inadvertent non-verbal behaviour (body language, proximity and eye contact) may seem insignificant, they may have a powerful impact on how comfortable and confident patients feel. If bias thwarts the establishment of patient-health provider rapport, this can have serious consequences for service delivery. Thus, even though the studies cited here indicate only a small proportion of health providers may express overtly racist attitudes towards Māori, there may be wider-spread bias throughout the healthcare system which is less obvious but still detrimental to Māori health outcomes.

\section{Stereotype threat}

Stereotype threat may be conceptualised as the fear of being judged based on group stereotypes or of confirming negative stereotypes of the group to which one belongs (Steele, 1997; Steele \& Aronson, 1995; Steele, Spencer, \& Aronson, 2002). Aronson et al. (2013) have applied stereotype threat to the health arena and suggest this accounts for why African American and other minority patients who have experienced bias in other settings can be particularly sensitive to discrimination in their dealings with health providers. Because stereotype threat promotes mistrust, minority patients may discount their health providers' advice if they see it is discriminatory. Moreover, they may even avoid seeking healthcare if they fear providers will stereotype them negatively (Aronson et al., 2013).

Stereotype threat that arises from repeated exposure to negative images/concepts in relation to Māori health and past experiences of discrimination may explain why Māori who need medical attention protect their self-esteem by avoiding situations where they feel they will be stereotyped again. Unfortunately, when it comes to health, New Zealanders are exposed to a range of negative stereotypes about Māori in the mainstream media (McCreanor et al., 2014). It is difficult to avoid portrayals of Māori in the popular press as being overweight, unhealthy (Jackson, 2013), smoking and drinking too much (Kearns, Moewaka Barnes, \& McCreanor, 2009), lacking in selfcare and "choosing" to not access medical services that would benefit them. Analyses of newspaper, television and radio reports demonstrate Māori are consistently presented as poorer and sicker as a group, largely due to lifestyle choices rather than structural issues or processes within the health system (Hodgetts, Masters, \& Robertson, 2004; McCreanor \& Nairn, 2002; Nairn et al., 2011).

Stereotype threat theory holds that minorities subject to negative health stereotypes may avoid healthcare out of a sense of shame, embarrassment and anxiety that they will be stereotyped by providers (Abdou \& Fingerhut, 2014). The potential for this concept to apply to Māori was revealed by the Māori Asthma Review (Pomare et al., 1991), which noted that Māori respondents often expressed a sense of apprehension or fear of being intimidated by doctors. The review discusses the concept of whakamā, or the feelings of shame and reluctance to seek medical help until it is absolutely necessary, which, they note, reflects a history of negative experiences with medical professionals.

A similar concept was raised by Cram, Smith and Johnstone (2003), who interviewed 28 Māori recruited from urban marae-based healthcare services. Overall, participants' experiences and knowledge of Pākehā doctors were not overly positive. Participants talked about whakamā as a potential barrier to healthcare; it may prevent people from going to see a doctor or, if they did see a doctor, prevent them from telling the doctor what was wrong with them. Jansen et al. (2008) also found that financial difficulties were not the only reason Māori did not go to the doctor. Māori reported that a key deterrent was embarrassment and a fear of being 
patronised. This coping mechanism to avoid bias is clearly problematic if Māori are missing out on healthcare that may be urgently required.

\section{Discussion and suggestions for further research}

Taken as a whole, this discussion suggests stereotyping, implicit bias and stereotype threat may be relevant to Māori health inequities in several ways. While it is not possible to make firm conclusions in the absence of empirical data, several observations come to mind:

1. Implicit biases may jeopardise the relationships that Māori clients have with Pākehā health providers (i.e., promote strained, awkward and less satisfying medical encounters). Poorer rapport means less information sharing so Māori may be less likely to give and receive important information, which may determine the way their health condition is managed and treated.

2. In medical encounters which are already subjective to stressors (i.e., time pressure, patient is in discomfort, fear of illness), it may be hard for misunderstandings between doctor and patient to be avoided. Consider in particular the feedback loop that could occur if the physician were to implicitly express bias and the Māori client were prone to stereotype threat.

3. In response to negative experiences with healthcare professionals, Māori may develop automatic defences to guard against more negative experiences. Māori may feel reluctant to engage with their healthcare providers. Providers may perceive Māori as less proactive, which they then mirror themselves.

While these are simply suggestions, if any of them hold truth then addressing implicit bias may be an important aspect of improving health outcomes for Māori. The extent to which implicit bias exists among different groups of healthcare professionals in New Zealand (i.e., doctors, nurses, specialists, maternity healthcare providers) needs to be more fully understood. Given direct examination of biases may be met with reluctance, it may be best to start with research which anonymises participant data. One technique used to clarify the link between health provider bias and treatment recommendations for Māori compared to non-Māori is to present healthcare providers with clinical vignettes in which patients' ethnicity (as Māori/nonMāori) has been randomly altered. Participants then complete the IAT so their scores can be correlated with treatment recommendations. This method has been used to detect variability based on ethnicity in international studies (e.g., Haider et al., 2015) and it is possible to replicate in New Zealand using online survey techniques.

Implicit bias may also affect treatment through its effects on interpersonal communication. As noted earlier, health providers with higher implicit biases are more likely to have poorer quality interpersonal interactions with patients. Possible research in the New Zealand context might explore micro-level interactions between clients and health providers; if implicit bias is found to be expressed through simple aspects of communication such as speed of speech or body positioning, specific training for clinicians may be suggested.

Research which explores the strategies Māori use to cope with bias is also needed. The aim of such research should be to identify ways Māori can mitigate bias and stereotype threat in order to constructively engage with healthcare providers.

In sum, in this paper I have clarified the role of implicit bias and stereotype threat for Māori health inequities. I have also demonstrated how recent research developments in the United States may elucidate the role of implicit bias for Māori health outcomes. Finally, I have discussed research methods which may shed light on appropriate interventions.

As a final comment, the ideas here are not 
meant to critique current approaches to providing cultural competency training to New Zealand health providers. Cultural competency training remains essential; however, the material covered here indicates implicit biases precede cultural competency and therefore a more sophisticated understanding of implicit biases is required.

According to Stone and Moskowitz (2011), contemporary training in cultural competence is insufficient to reduce health inequities because even educated, culturally sensitive individuals can activate and use their biases without being aware they are doing so. They argue that problems can be reduced by workshops and learning modules that focus on the psychology of non-conscious bias. Burgess, Van Ryn, Dovidio and Saha (2007) outline a number of important steps towards addressing unconscious bias among health providers. Research with American-based samples has found that individuals who are committed to reducing bias are more likely to want to selfevaluate and take action to reduce their bias. As a first step, they recommend helping providers understand the cognitive bases of biases, openly acknowledging stereotypes, enhancing health providers' confidence in their ability to interact with patients from a different cultural background, and enhancing provider empathy (see also Perry, Murphy, \& Dovidio, 2015, for further discussion).

Currently, any discussions of racism are met with resistance; however, given the significant amount of work which has demonstrated that even those who are consciously fair-minded are less magnanimous than they think are, exploring this further in the New Zealand health system may encourage discussions around racism which are less threatening and may elicit engagement from Pākehā and Māori alike.

\section{Glossary}

$\begin{array}{ll}\text { hui } & \text { meeting } \\ \text { marae } & \text { tribal meeting grounds } \\ \text { Pākehā } & \text { a person of predominantly } \\ & \quad \text { European descent } \\ \text { whakamāa } & \text { shy; ashamed/shame(d) }\end{array}$




\section{References}

Abdou, C., \& Fingerhut, A. (2014). Stereotype threat among Black and White women in health care settings. Cultural Diversity and Ethnic Minority Psychology, 20(3), 316-323. http://doi.org/bt38

Alexander, H., Irwin, C., Purdie, G., \& Hunn, M. (2010). Incidence and management of high grade glioma in Māori and non-Māori patients. Journal of Clinical Neuroscience, 17(9), 1144-1147. http://doi.org/c93hzf

Amodio, D. M. (2014). The neuroscience of prejudice and stereotyping. Nature Reviews Neuroscience, 15(10), 670-682. http://doi.org/bt39

Armbrister, A. (2014). The influence of discriminatory beliefs on practice (Unpublished doctoral dissertation). Columbia University, New York.

Aronson, J., Burgess, D., Phelan, S. M., \& Juarez, L. (2013). Unhealthy interactions: The role of stereotype threat in health disparities. American Journal of Public Health, 103(1), 50-56. http:// doi.org/bt $4 b$

Arroll, B., Goodyear-Smith, F., \& Lloyd, T. (2002). Depression in patients in an Auckland general practice. New Zealand Medical Journal, 115(1152), 176-179.

Banaji, M. R. (2013). Our bounded rationality. In J. Brockman (Ed.), This explains everything: Deep, beautiful, and elegant theories of how the world works (pp. 94-94). New York, NY: Harper Perennial.

Blair, I. V., Steiner, J. F., Fairclough, D. L., Hanratty, R., Price, D. W., Hirsch, H. K., .. . Havranek, E. P. (2013). Clinicians' implicit ethnic/racial bias and perceptions of care among black and Latino patients. Annals of Family Medicine, 11(1), 43-52. http://doi.org/bt4c

Blair, I. V., Steiner, J. F., Hanratty, R., Price, D. W., Fairclough, D. L., Daugherty, S., . . Havranek, E. P. (2014). An investigation of associations between clinicians' ethnic or racial bias and hypertension treatment, medication adherence and blood pressure control. Journal of General Internal Medicine, 29(7), 987-995. http://doi. org/bt4d

Blair, I. V., Steiner, J. F., \& Havranek, E. P. (2011). Implicit (implicit) bias and health disparities: Where do we go from here? Permanente Journal, 15(2), 71-78.

Bramley, D., Riddell, T., Crengle, S., Curtis, E., Harwood, M., Nehua, D., \& Reid, P. (2004). A call to action on Māori cardiovascular health.
New Zealand Medical Journal, 117(1197): U957.

Brewer, N., Zugna, D., Daniel, R., Borman, B., Pearce, N., \& Richiardi, L. (2012). Which factors account for the ethnic inequalities in stage at diagnosis and cervical cancer survival in New Zealand? Cancer Epidemiology, 36(4), e251-e257. http://doi.org/bt4f

Brown, R. (2016). Fear at heart of failure to act on institutional racism and disparity. New Zealand Doctor Online. Retrieved from http://www. nzdoctor.co.nz

Burgess, D., Van Ryn, M., Dovidio, J., \& Saha, S. (2007). Reducing racial bias among health care providers: Lessons from social-cognitive psychology. Journal of General Internal Medicine, 22(6), 882-887. http://doi.org/c64mtw

Came, H. (2012). Institutional racism and the dynamics of privilege in public bealth (Unpublished $\mathrm{PhD}$ thesis). Waikato University, Hamilton, New Zealand.

Came, H. (2014). Sites of institutional racism in public health policy making in New Zealand. Social Science and Medicine, 106, 214-220. http:// doi.org/bt4g

Chambers, J. W., Kambon, K., Birdsong., B. D., Brown, J., Dixon, P., \& Robbins-Brinson, L. (1998). Africentric cultural identity and the stress experience of African American college students. Journal of African-American Psychology, 24(3), 368-396. http://doi.org/bt3m2p

Cooper, L. A., Roter, D. L., Carson, K. A., Beach, M. C., Sabin, J. A., Greenwald, A. G., \& Inui, T. S. (2012). The associations of clinicians' implicit attitudes about race with medical visit communication and patient ratings of interpersonal care. American Journal of Public Health, 102(5), 979-987. http://doi.org/bt4h

Cram, F., Smith, L., \& Johnstone, W. (2003). Mapping the themes of Maori talk about health. New Zealand Medical Journal, 116(1170), 357-363.

Curtis, E., Wikaire, E., Jiang, Y., McMillan, L., Loto, R., Airini, \& Reid, P. (2015). A tertiary approach to improving equity in health: Quantitative analysis of the Māori and Pacific Admission Scheme (MAPAS) process, 2008-2012. International Journal for Equity in Health, 14, 1-15. http:// doi.org/bt4j

Dovidio, J. F., \& Gaertner, S. L. (2010). Intergroup bias. In S. T. Fiske, D. T. Gilbert, \& G. Lindzey (Eds.), Handbook of social psychology (5th ed., pp. 1084-1121). Hoboken, NJ: Wiley. http:// doi.org/bt4k 
Dovidio, J. F., Kawakami, K., \& Gaertner, S. L. (2002). Implicit and explicit prejudice and interracial interaction. Journal of Personality and Social Psychology, 82(1), 62-68. http://doi.org/cnddbn

Ellison-Loschmann, L., Firestone, R., Aquilina, L., McKenzie, F., Gray, M., \& Jeffreys, M. (2015). Barriers to and delays in accessing breast cancer care among New Zealand women: Disparities by ethnicity. BMC Health Services Research, 15, 1-8. http://doi.org/bt4m

Ellison-Loschmann, L., \& Pearce, N. (2000). Pacific Health Dialog., 7(1), 82-93.

Green, A. R., Carney, D. R., Pallin, D. J., Ngo, L. H., Raymond, K. L., Iezzoni, L. I., \& Banaji, M. R. (2007). Implicit bias among physicians and its prediction of thrombolysis decisions for black and white patients. Journal of General Internal Medicine, 22(9), 1231-1238. http:// doi.org/csnfwn

Greenwald, A. G., \& Banaji, M. R. (1995). Implicit social cognition: Attitudes, self-esteem, and stereotypes. Psychological Review, 102(1), 4-27. http://doi.org/gmt

Greenwald, A. G., \& Banaji, M. R. (2013). Blindspot: Hidden biases of good people. New York, NY: Delacorte.

Greenwald, A. G., Banaji, M. R., Rudman, L., Farnham, S., Nosek, B. A., \& Mellott, D. (2002). A unified theory of implicit attitudes, stereotypes, selfesteem, and self-concept. Psychological Review, 109(1), 3-25. http://doi.org/bvjp8f

Greenwald, A. G., McGhee, D. E., \& Schwartz, J. K. L. (1998). Measuring individual differences in implicit cognition: The implicit association test. Journal of Personality and Social Psychology, 74(6), 1464-1480. http://doi.org/gmv

Greenwald, A. G., Poehlman, T. A., Uhlmann, E. L., \& Banaji, M. R. (2009). Understanding and using the Implicit Association Test: III. Meta-analysis of predictive validity. Journal of Personality and Social Psychology, 97(1), 17-41. http://doi. org/c8c9rj

Haider, A., Schneider, E., Sriram, N., Scott, V., Swoboda, S., Zogg, C. Dhiman, N., . . . Cooper, L. A. (2015). Unconscious race and class biases among registered nurses: Vignette-based study using implicit association testing. Journal of the American College of Surgeons, 220(6), 1077-1086. http://doi.org/bt4n

Hall, W. J., Chapman, M. V., Lee, K. M., Merino, Y. M., Thomas, T. W., Payne, B. K., .. . CoyneBeasley, T. (2015). Implicit racial/ethnic bias among health care professionals and its influence on health care outcomes: A systematic review. American Journal of Public Health, 105(12), e60-e76. http://doi.org/bt4p

Harris, R., Cormack, D., \& Stanley, J. (2013). The relationship between socially-assigned ethnicity, health and experience of racial discrimination for Māori: Analysis of the 2006/07 New Zealand Health Survey. BMC Public Health, 13, 1-8. http://doi.org/bt4r

Harris, R., Cormack, D., Tobias, M., Yeh, L., Talamaivao, N., Minster, J., \& Timutimu, R. (2012). Self-reported experience of racial discrimination and health care use in New Zealand: Results from the 2006/07 New Zealand Health Survey. American Journal of Public Health, 102(5), 1012-1019. http://doi.org/bt4q

Harris, R., Tobias, M., Jeffreys, M., Waldgrave, K., Karlsen, S., \& Nazroo, J. (2006). Effects of selfreported racial discrimination and deprivation on Māori health inequalities in New Zealand: Cross-sectional study. The Lancet, 367(9527), 2005-2009. http://doi.org/dbj2wn

Hill, S., Sarfati, D., Blakely, T., Robson, B., Purdie, G., Chen, J., . . Kawachi, I. (2010). Survival disparities in Indigenous and non-Indigenous New Zealanders with colon cancer: The role of patient comorbidity, treatment and health service factors. Journal of Epidemiology and Community Health, 64(2), 117-123. http://doi. org/c6kx3b

Hill, S., Sarfati, D., Blakely, T., Robson, B., Purdie, G., Dennett, E., . . . Kawachi, I. (2010). Ethnicity and management of colon cancer in New Zealand: Do indigenous patients get a worse deal? Cancer, 116(13), 3205-3214. http://doi.org/c2twt5

Hodgetts, D., Masters, B., \& Robertson, N. (2004). Media coverage of "decades of disparity" in ethnic mortality in Aotearoa. Journal of Community and Applied Social Psychology, 14(6), 455-472. http://doi.org/b2nzd2

Jackson, W. (2013, June 07). Racial stereotypes pervade. Stuff. Retrieved from http://www.stuff. co.nz

Jansen, P., Bacale, K., \& Crengle, S. (2008). He Ritenga Whakaaro: Māori experiences of health services. Auckland, New Zealand: Mauri Ora.

Jansen, P., \& Jansen, D. (2013). Māori and health. In I. St George (Ed.), Cole's medical practice in New Zealand (12th ed., pp. 52-65). Wellington, New Zealand: Medical Council of New Zealand.

Johnstone, K., \& Read, J. (2000). Psychiatrists' recommendations for improving bicultural training and Māori mental health services: A New Zealand 
survey. Australian and New Zealand Journal of Psychiatry, 34(1), 135-145. http://doi.org/ bn6r9f

Joiner, T., Katz, J., \& Kwon, P. (2002). Membership in a devalued social group and emotional well-being: Developing a model of personal self-esteem, collective self-esteem, and group socialization. Sex Roles: A Journal of Research, 47(9), 419-431.

Jones, R. G., Henning, M. A., Pinnock, R., Shurluf, B., \& Hawken, S. J. (2013). Medical students' and clinical teachers' perceptions of Māori health teaching. New Zealand Medical Journal, 126(1377), 41-50.

Kearns, R., Moewaka Barnes, H., \& McCreanor, T. (2009). Placing racism in public health: A perspective from Aotearoa/New Zealand. GeoJournal, 74(2), 123-129. http://doi.org/fvzj38

Lynch, J. W., Davey Smith, G., Kaplan, G. A., \& House, J. S. (2000). Income inequality and mortality: Importance to health of individual income, psychosocial environment, or material conditions. British Medical Journal, 320(7243), 1200-1204. http://doi.org/bkkgz7

Marriott, L., \& Sim, D. (2014). Indicators of inequality for Māori and Pacific people (No. 09/2014 Working Papers in Public Finance). Victoria University of Wellington, Wellington, New Zealand.

McCreanor, T., \& Nairn R. (2002). Tauiwi general practitioners' talk about Māori health: Interpretative repertoires. New Zealand Medical Journal, 115(1167), 1-8.

McCreanor, T., Rankine, J., Moewaka Barnes, A., Borell, B., Nairn, R., \& McManus, A. (2014). The association of crime stories and Māori in Aotearoa New Zealand print media. Sites, 11(1), 121-144. http://doi.org/bt4s

Ministry of Health. (2004). Report on maternity: Maternal and newborn information. Retrieved from https:/www.health.govt.nz/system/files/ documents/publications/maternityreport04.pdf

Ministry of Health. (2014). Equity of health care for Māori: A framework. Wellington, New Zealand: Author.

Ministry of Health. (2015). Tatau kahukura: Māori bealth chart book 2015 (3rd ed.). Wellington, New Zealand: Author.

Mitchell, E. (1991). Racial inequalities in childhood asthma. Social Science \& Medicine, 32(7), 831-836. http://doi.org/cvsq6n

Nairn, R., Moewaka Barnes, A., Rankine, J., Borell, B., Abel, S., \& McCreanor, T. (2011). Mass media in Aotearoa: An obstacle to cultural competence.
New Zealand Journal of Psychology, 40(3), 168-175.

Oswald, F. L., Mitchell, G., Blanton, H., Jaccard, J., \& Tetlock, P. E. (2013). Predicting ethnic and racial discrimination: A meta-analysis of IAT criterion studies. Journal of Personality and Social Psychology, 105(2), 171-192. http://doi.org/bt4t

Pacific Perspectives. (2013). Maternity care experiences of teen, young, Māori Pacific and vulnerable mothers at Counties Manukau Health. Wellington, New Zealand: Pacific Perspectives.

Paradies, Y., Truong, M., \& Priest, N. (2014). A systematic review of the extent and measurement of healthcare provider racism. Journal of General Internal Medicine, 29(2), 364-387.

Perry, S. P., Murphy, M. C., \& Dovidio, J. F. (2015). Modern prejudice: Subtle, but unconscious? The role of bias awareness in Whites' perceptions of personal and others' biases. Journal of Experimental Social Psychology, 61, 64-78. http://doi.org/bt4v

Pomare, E., Tutengahe, H., Ramsden, I., Hight, M., Pearce, N., \& Ormsby, V. (1991). He Mate Huango: Māori Asthma Review. Wellington, New Zealand: Huia.

Obertová, Z, Lawrensen, R., Scott, N., Holmes, M., Brown, C., Chunhuan, L., ... Gilling, P. (2015). Treatment modalities for Māori and New Zealand European men with localised prostate cancer. International Journal of Clinical Oncology, 20(4), 814-820. http://doi.org/bt4w Reilly, J. B., Ogdie, A. R., Von Feldt, J. M., \& Myers, J. S. (2013). Teaching about how doctors think: A longitudinal curriculum in cognitive bias and diagnostic error for residents. BMJ Quality \& Safety, 22(12), 1044-1050. http://doi.org/bt4x Sabin, J. A., \& Greenwald, A. (2012). A vague unease: The influence of implicit bias on treatment recommendations for 4 common pediatric conditions: Pain, urinary tract infection, attention deficit hyperactivity disorder, and asthma. American Journal of Public Health, 102(5), 988-995. http://doi.org/bt4z

Sabin, J. A., Nosek, B. A., Greenwald, A. G., \& Rivara, F. P. (2009). Physicians' implicit and explicit attitudes about race by MD race, ethnicity and gender. Journal of Health Care for the Poor and Underserved, 20(3), 896-913. http://doi. org/b8mrb5

Sneyd, M. (2008). Ethnic differences in prostate cancer survival in New Zealand: A national study. Cancer Causes \& Control, 19(9), 993-999. http://doi.org/fbrq $8 b$ 
Steele, C. M. (1997). A threat in the air: How stereotypes shape intellectual identity and performance. American Psychologist, 52(6), 613-629. http:// doi.org/br4sk4

Steele, C. M., \& Aronson, J. (1995). Stereotype threat and the intellectual test performance of African Americans. Journal of Personality and Social Psychology, 69(5), 797-811. http://doi.org/ cj4g2w

Steele, C. M., Spencer, S. J., \& Aronson, J. (2002). Contending with group image: The psychology of stereotype and social identity threat. In M. P. Zanna (Ed.), Advances in experimental social psychology (pp. 379-440). San Diego, CA: Academic Press.

Stone, J., \& Moskowitz, G. B. (2011). Non-conscious bias in medical decision making: What can be done to reduce it? Medical Education, 45(8), 768-776. http://doi.org/b3xh9b

Tajfel, H., \& Turner, J. (1986). The social identity theory of intergroup behaviour. In S. Worchel \& W. G. Austin (Eds.), Psychology of intergroup relations (pp. 7-24). Chicago, IL: Nelson Hall.
Tatum, B. D. (1997). Why are all the Black kids sitting together in the cafeteria? New York, NY: Basic.

Teal, C., Gill, A., Green, A., \& Crandall, S. (2012). Helping medical learners recognise and manage unconscious bias toward certain patient groups. Medical Education, 46(1), 80-88. http://doi. org/dfv4bt

Walker, T., Signal, L., Russell, M., \& Tuhiwai-Ruru, R. (2008). The road we travel: Māori experience of cancer. New Zealand Medical Journal, 121(1279), 27-35.

Westbrooke, I., Baxter, J., \& Hogan, J. (2001). Are Māori under-served for cardiac interventions? New Zealand Medical Journal, 114(1143), 484-487.

Zestcott, C. A., Blair, I. V., \& Stone, J. (2016). Examining the presence, consequences, and reduction of implicit bias in health care: A narrative review. Group Processes \& Intergroup Relations, 19(4), 528-542. 